\title{
ПОНЯТИЕ ЭЛЕКТРОННЫХ ЦЕННЫХ БУМАГ В МЕЖДУНАРОДНОМ ПРАВЕ
}

\author{
(c) 2021 Якуб Фаиз \\ аспирант, Юридический факультет \\ Санкт-Петербургский государственный университет, Россия, Санкт-Петербург \\ E-mail: faiz84waheeb@gmail.com
}

Цель исследования заключается в определении понятия и признаков электронных ценных бумаг на международном уровне. Предметом изучения выступили Гаагская и Женевская конвенции по ценным бумагам. В настоящее время понятие электронных ценных бумаг опирается на экономические, а не правовые критерии. Единственным признаком ценных бумаг, закреплённым в международных конвенциях, является их финансовый характер. Перечень электронных ценных бумаг носит расплывчатый характер и охватывает все финансовые активы и инструменты, за исключением денежных средств. Как следствие невозможно выделить электронные ценные бумаги из совокупности имущественных прав в целом.

Ключевые слова: электронная ценная бумага, финансовый актив, финансовый инструмент, Гаагская Конвенция, Женевская Конвенция.

В настоящее время институт ценных бумаг переживает серьезные изменения, поскольку исчезают системные его признаки, из которых складывается само понятие ценных бумаг.

Как отмечает М.В.Самойлова, впервые понятие «ценная бумага» появляется в Германии в учебнике Бринкмана по торговому праву 1853 года $[10$, с. 122]. На законодательном уровне ценная бумага упоминается в 1861 году в п. $1 \S .271$ Общегерманского торгового уложения [3].

Под ценной бумагой понимался любой документ имущественно-правового содержания. В дальнейшем в 1882 году Бруннер предложил определение ценных бумаг, которое не потеряло своего значения и сегодня. Согласно нему, ценная бумага - это документ о частном праве, реализация которого зависит от обладания частноправовым документом [8, с. 5-6]. Исходя из этого определения только обладатель (держатель) ценной бумаги в виде документа может реализовать свои права: получить имущество, обеспечить свои требования по другим обязательствам. Если у лица нет на руках ценной бумаги, то и осуществить свои права он не может. По сути, нет документа (ценной бумаги) - нет и права.

М.М.Агарков отмечал, что Бруннер указал на особенность, которая «позволяет объединить в одном понятии все разнообразие отдельных видов ценных бумаг» [4, с. 180]. В дальнейшем Якоби внес изменения в представленную формулу и описал ценную бумагу как документ, предъявление которого необходимо для осу- ществления выраженного в нем права. Подобное определение получило распространение в Италии и Швейцарии [10, с. 123]. Таким образом, права, которые дает ценная бумага, реализуются только при предъявлении документа. Иными словами, осуществление прав, их защита, передача другим лицам и иные действия возможны только при контроле над документом (ценной бумагой).

Однако закрепление ценных бумаг в электронной (бездокументарной) форме, получившее широкое распространение в последние десятилетия, привело к изменению существующих правил. Теперь не требуется предъявлять ценную бумагу в виде документа для осуществления прав из неё.

Переход ценных бумаг в бездокументарный вид начался в 1980-е годы и получил особенно бурное развитие уже в XXI веке. Подобная трансформация происходила двумя путями, которые часто дополняли друг друга и описаны Бернаскони К. и Сигманом Х.Г [5, с. 70-72].

Первый из них дематериализация как исключение или упразднение любых бумажных документов на ценные бумаги. Второй - это иммобилизация, то есть прекращение передачи документарных ценных бумаг. Электронные ценные бумаги теперь находятся в специальных хранилищах (депозитариях) и существуют как запись в реестре.

Более того, в настоящее время ведение счета и все операции с ценными бумагами осущест- 
вляет специальный посредник. Если раньше для осуществления прав из ценной бумаги ею надо было владеть, то сейчас это не обязательно. Все действия от имени собственника ведут посредники, которых может быть несколько, и они находятся в разных странах.

Иными словами, два ключевых признака ценной бумаги - документарный вид и необходимость прямого владения ею потеряли свое значение. Между тем именно на основе этих двух признаков и формулировалось понятие классической ценной бумаги. Возникшую проблему пытаются решить как на национальном, так и на международном уровнях.

В рамках международного частного права общий подход был предложен в рамках Гаагской конвенции о праве, применимом к определенным правам на ценные бумаги, находящиеся во владении посредника. Она появилась 5 июля 2006 года, вступила в силу в 2017 году и получила краткое название - Гаагская конвенция по ценным бумагам (далее - Гаагская конвенция).

Определение ценных бумаг изложено в самом начале Гаагской конвенции (п. «а» ст. 1). Ценные бумаги означают любые акции, облигации или другие финансовые инструменты или финансовые активы (кроме денежных средств), а также любые проценты по ним.

Финансовый инструмент представляет собой договор или контракт, по которому одновременно возникают финансовый актив у одной компании и финансовое обязательство,- у другой. K финансовым инструментам относятся дебиторская и кредиторская задолженность в традиционных формах и в виде векселей, облигаций, иных долговых ценных бумаг, долевые ценные бумаги, а также производные формы, различные финансовые опционы, фьючерсные и форвардные контракты, процентные и валютные свопы. Авали по векселям, иные гарантии по исполнению обязательств другими лицами относятся к условным финансовым инструментам.

Решающим фактором, определяющим признание финансовых инструментов, является не юридическая форма, а экономическое содержание такого инструмента.

Финансовые активы - это денежные средства или договорные права требовать выплаты денежных средств или передачи финансовых инструментов от другой лица на выгодных для себя условиях.

С токи зрения экономики финансовые ин- струменты - это квазиденьги, а финансовый актив - способ получения дохода.

Электронные ценные бумаги ввиду их нематериального характера и потери прямой связи с собственником могут рассматриваться одновременно как финансовые активы и финансовые инструменты. Это относится в первую очередь к долговым и долевым (акции) ценным бумагам. При обсуждении проекта Гаагской конвенции ставился вопрос об разграничении финансовых активов и инструментов, однако решение найти не удалось.

По мнению К.Бернаскони и Х. Сигмана, несмотря на то, что прямо упоминаются в качестве разновидностей ценных бумаг только облигации и акции, к числу финансовых активов можно отнести и целый ряд других объектов.

В частности, в состав электронных ценных бумаг включают все биржевые активы - кредитные деривативы, американские депозитарные расписки, варранты, опционы и фьючерсы, инвестиционные паи. Кроме того, безусловно, под регулирование Гаагской конвенции подпадают и векселя [5, с. 82].

Следовательно, все виды долевых и долговых ценных бумаг, которые зачисляются на специальный счет через посредника, подпадают под действие Гаагской конвенции. Не имеет значения, являются ли ценные бумаги на предъявителя или зарегистрированными, представлены ли они сертификатом или дематериализованы. Способ выпуска ценных бумаг не имеет значения.

Иными словами в Гаагской Конвенции предусмотрен максимальный широкий охват финансовых активов, в том числе и тех, которые могут появиться в дальнейшем с развитием экономических связей и технологий. В настоящее время любой биржевой актив и инструмент, выраженный в электронной форме, независимо от своего названия, предназначения и распространения должен быть отнесен к бездокументарным ценным бумагам. При этом подобные активы используются гораздо чаще и распространены куда сильнее, чем классические виды ценных бумаг, уходящие корнями еще в документарную эпоху.

Таким образом, основным и, по сути, единственным признаком электронной ценной бумаги на котором строится её понятие, выступает финансовый характер. Это экономическая, а не правовая категория. Более того, в Гаагской кон- 
венции намеренно не приводится критериев, разграничивающих электронные ценные бумаги от иных финансовых активов и инструментов. Не приводится даже примерный перечень ценных бумаг. По признанию разработчиков Гаагской конвенции это сделано специально, поскольку изменения в рыночной практике идут постоянно и появляются новые финансовые инструменты, которые могут признаваться ценными бумагами.

Вследствие этого нельзя говорить о четком определении электронной ценной бумаги в Гаагской конвенции с правовой точки зрения. Не представляется возможным на основе терминологии отделить ценные бумаги от других объектов гражданских прав в первую очередь имущественных прав.

Гаагская Конвенция является основным международным соглашением, регулирующим статус электронных ценных бумаг. В качестве другого источника можно рассматривать Конвенцию УНИДРУА о материально-правовых нормах, касающихся опосредованно удерживаемых ценных бумаг. 2009 года. Она пока не вступила в силу. Её сокращённое название - Женевская Конвенция по ценным бумагам (далее - Женевская Конвенция).

Согласно п. а ст. 1 Женевской Конвенции «ценные бумаги» означают любые акции, облигации или другие финансовые инструменты или финансовые активы (кроме денежных средств), которые могут быть зачислены на счет ценных бумаг и приобретены и отчуждены в соответствии с положениями настоящей Конвенции.

Единственным отличием и дополнением по сравнению с Гаагской конвенцией в области терминологии выступает возможность ценных бумаг приобретаться и отчуждаться другими лицами, то есть переход ценных бумаг от одних субъектов гражданского права к другим. Однако подобная возможность, разумеется, презюмируется в Гаагской конвенции, особенно в правилах, посвященных регулированию деятельности посредника, поэтому рассматриваемое дополнение нельзя признать существенным.

Таким образом, в целом определение ценных бумаг в Женевской Конвенции дублирует Гаагскую конвенцию.

Однако в Женевской Конвенции появляется ранее неизвестное определение «промежуточные ценные бумаги». Под ним понимают ценные бумаги, зачисленные на счет ценных бумаг, или права или доли в ценных бумагах, возникающие в результате зачисления ценных бумаг на счет ценных бумаг. К числу таких бумаг следует отнести ценные бумаги, находящиеся в опосредованном владении посредника. Поскольку подавляющее большинство ценных бумаг сейчас размещаются на счетах, принадлежащих посредникам, именно промежуточным ценным бумагам посвящена в основном Женевская конвенция.

При этом, по справедливому замечанию А. Выговского в Женевской Конвенции в отношении промежуточных ценных бумаг действует не только обязательственно-правовой статут, но и допускается применение к опосредованному владению электронными ценными бумагами как обязательственных, так и вещных правомочий [6, с. 119].

Таким образом, получается, что у посредников могут формироваться ограниченные вещные права в отношении «чужой» ценной бумаги или складывается институт, аналогичный доверительной собственности. Происходит усиление позиций посредника за счет собственника электронных ценных бумаг.

В целом необходимо отметить, что понятие ценных бумаг, закрепленное в Женевской конвенции, не позволяет выделить дополнительные её признаки по равнению с Гаагской конвенцией.

Подводя итоги, следует признать, что в настоящее время понятие электронных ценных бумаг в международном частном праве опирается на экономические, а не юридические критерии. Главным является финансовый характер ценной бумаги, которая может выступать как финансовым активом, так и финансовым инструментом. При этом разграничение актива и инструмента в конвенциях не производится.

Более того, электронные ценные бумаги не отделяются от остальных финансовых активов и инструментов. В результате нельзя на сегодняшний день составить перечень электронных ценных бумаг, в перспективе не исключается появление новых их видов.

Как следствие электронные ценные бумаги в международном частном праве невозможно выделить из состава таких объектов гражданских прав как имущественные права. Проблематика определения понятия и признаков электронных ценных бумаг на современном этапе еще ждет своего разрешения. 


\section{Библиографический список}

1. Гаагская конвенция о праве, применимом к определенным правам на ценные бумаги, находящиеся во владении посредника 2006 год // https://www.hcch.net/en/instruments/conventions/full-text/?cid=72.

2. Конвенция УНИДРУА о материально-правовых нормах, касающихся опосредованно удерживаемых ценных бумаг. 2009 года // https://www.unidroit.org/english/conventions/2009intermediatedsecurities/convention. pdf.

3. Общегерманский торговое уложение // https://infopedia.su/7x3abc.html.

4. Агарков М. М. Основы банковского права. Учение о ценных бумагах, М: БЕК, 1994-350с.

5. Бернаскони К., Сигман Х.Г. Гаагская конвенция о праве, применимом к определенным правам на ценные бумаги, находящиеся во владении посредника // Государство и право.- М.: Наука, 2006, № 12.- С. $70-87$.

6. Выговский А. Унификация материально-правовых норм в рамках Конвенции УНИДрУА о ценных бумагах 2009 года // Хозяйство и право 2010 № 3 с. 117-123.

7. Набиуллина Ю.Р. Особенности учетной системы бездокументарных ценных бумаг в германском праве // Финансовое право и управление 2017 № 2 с. 57-73.

8. Родионова О. М. Правовой институт ценных бумаг: Учебное пособие. Саранск: Красный октябрь, 2002-72с.

9. Рубцов Б. Б. Финансовый рынок Франции // Портфельный инвестор 2009 № 3-4. С. 1-19.

10. Самойлова М.В. Бездокументарные ценные бумаги в правовой доктрине Германии // Закон России Опыт, анализ, практика 2007 № 8 с. 122-127.

11. Туктаров Ю.Е. Ценные бумаги в контексте истории фондового рынка // Закон. 2006. № 7. С. $24-29$.

12. Юркова Е.В. Правовое регулирование бездокументарных ценных бумаг: историко-правовой анализ // Проблемы экономики и юридической практики 2017 № 2 с. 157-160. 